\title{
Investigating the online and offline contexts of day-to-day democracy as participation spaces
}

\author{
Dr Ella Taylor-Smith and Dr Colin F. Smith
}

School of Computing, Edinburgh Napier University, Edinburgh, UK.

Corresponding author: Ella Taylor-Smith, School of Computing, Edinburgh Napier University, 10, Colinton Road, Edinburgh, EH10 5DT, UK

Email: e.taylor-smith@napier.ac.uk; ORCID: 0000-0003-3407-1029; Twitter: @EllaTasm

Colin Smith, School of Computing, Edinburgh Napier University, 10, Colinton Road, Edinburgh, EH10 5DT, UK

Email: cf.smith@napier.ac.uk; ORCID: 0000-0003-0362-2254

\section{Biographical Notes}

Dr Ella Taylor-Smith is Senior Research Fellow in Edinburgh Napier University's School of Computing. Ella explores online and offline spaces, and the relationships between them, in the context of grassroots democracy.

Dr Colin F Smith is Senior Lecturer in the School of Computing at Edinburgh Napier University. His research examines the relationships between information and communication technologies, innovation and organisational change, particularly in the contexts of e-government and e-democracy. 


\title{
Investigating the online and offline contexts of day-to-day democracy
}

\section{as participation spaces}

\begin{abstract}
Citizen-led participation in democracy is explored through studying the online and offline spaces where people work together to influence those in power and improve their communities. The concept of a participation space is introduced to describe these contexts. The spatial theme guides the research, from literature, through methodology, to findings. Case studies of three community/ activist groups provide the data to identify participation spaces and model these as SocioTechnical Interaction Networks (STINs) (Kling, McKim, \& King, 2003). These participation spaces include social media, email, and blogs, as well as paper media and offline spaces, such as rooms. The STIN models of these participation spaces reveal that the characteristics which influence their use for participation are the same for online and offline spaces. These can be understood in terms of spatial characteristics: the spaces' perceived boundaries and inhabitants, combined with ownership and access, including costs. As well as recording the roles of these spatial characteristics, the participation space models map the dayto-day activities of participation. Collating these activities reveals that participation primarily takes the form of communication: organising and increasing solidarity, sharing information, encouraging involvement, and trying to influence events. The models also reveal that most of these activities are nonpublic. This socio-technical study describes the relationship between the activities of local, grassroots democracy and the characteristics of the online and offline spaces where it takes place.
\end{abstract}

Keywords: eParticipation, democracy, social media, STIN, assemblage, social informatics

\section{Introduction}

This study establishes the concept of a participation space, in order to study online and offline spaces which support grassroots democracy, increasing our understanding of contemporary participation. The three case studies are diverse local groups, working together to improve their communities, through influencing local authority decisions 
and collaborative action. This is a vital component of our democracy (Williamson, 2011). While we grapple with Internet-enabled obstacles to democracy, such as media manipulation or "fake news" (Marwick \& Lewis, 2017), it is also important to understand the various ways in which the Internet supports people's participation in democracy, as well as the myriad influences and potential exclusions of emergent contexts such as social media. To this end, rather than focus on the structure of the campaigning groups (e.g. Bennett \& Segerberg, 2012) or on ideals of participation (e.g. Arnstein, 1969), this study investigates the spaces where the groups meet and communicate. The Socio-Technical Interaction Network (STIN) methodology (Kling, McKim, \& King, 2003) guides a thorough investigation of these participation spaces, leading to a collection of context-rich models of these online and offline spaces - their component parts, activities, and timelines.

Focusing on participation spaces follows the tradition of using space and place metaphors to understand Internet phenomena (Arora, 2014; Dodge \& Kitchin, 2001). The spatial focus encourages a non-hierarchical investigation of the elements that make up and influence each context. It also enables online and offline contexts to be considered using the same framework. Arora, in a similar way, compares online spaces to public parks (2014), revealing that many concerns about Internet spaces, especially social media, closely resemble those encountered, historically, by the developers and managers of parks. Arora describes generations of people appropriating parks for political action and park managers trying to balance freedom of expression with other visitors' expectations of leisure space. The comparison increases our understanding of the need to balance safety and privacy with freedom, control, and exclusion. It also encourages us, before retreating into dystopian narratives, to consider who has the responsibility and agency to manage online contexts. 


\section{Overview of the study}

Participation spaces are defined by the activities which take place in them, specifically participation in democracy. In this study, focusing on community activism, democratic participation is understood broadly, from informal day-to-day interactions to formal opportunities provided by institutions, and participation is identified as the activities people undertake to further the aims of their groups. Online participation spaces, identified this way, include websites, blogs, social media, and email. Offline participation spaces include paper media and physical spaces, indoors and outside. Participation spaces are sociotechnical systems: assemblages of heterogeneous elements (e.g., social, technical, and economic), with relevant histories and trajectories of development and use. Each space is a composite of people, artefacts, and processes, including expectations of behaviour.

The STIN studies of participation spaces, described below, provide new insights into contemporary democracy, revealing the day-to-day activities of democracy and the relationship between the case-study groups and the technologies they use to support their work. For example: ownership, cost, and people's confidence in the boundaries of each space influence both the style and volume of their involvement, and the usefulness of the space to the group. The participation space concept supports the application of established (and contested) ideas to the contemporary contexts of democracy online. Cornwall considers involvement and power (2002); Goffman illustrates the influence of observation, describing spaces as essentially either used for public performance or preparation with the team (1971/1959); evolutions of the public sphere draw attention to inclusion and sociality. These characteristics of spaces in democracy are explored below. 


\section{Contextualising participation spaces}

\section{Ownership}

Many considerations of democratic participation centre on initiatives or events created specifically for that purpose, whether by those in power wishing to consult (top-down) or citizens trying to influence events (grassroots). Cornwall draws out the influences of ownership and control by characterising participation initiatives, which are organised by authorities or institutions, as invited spaces (Cornwall, 2000). Citizens are invited to take part, but the spaces are "framed by those who create them, and infused with power relations and cultures of interaction carried into them from other spaces" (Cornwall \& Coehlo, 2007, p. 11). Cornwall contrasts these with created spaces: initiatives which are created and managed by citizens. Hassan echoes this dual conceptualisation, specifically referring to the Scottish context, in his unspace and fuzzy, messy spaces (2014, pp. 6466). Unspace describes the awkward formal spaces of democracy, where people wear name badges and express opinions aligned to their institutional mandates. Fuzzy, messy spaces describe people coming together out of interest, talking as individuals, in everyday terms. Hassan notes how unspace excludes certain people, behaviour, and opinions.

Cornwall's choice of the term created for participation organised by citizens is reflected in the umbrella concept of DIY Citizenship (Hartley, 2010; Ratto \& Boler, 2014), applied to diverse grassroots activities, beyond processes of democracy which centre on elections and elected representatives. DIY Citizenship emphasises the agency and creativity of citizens, establishing processes and using or creating spaces (on and offline) to suit themselves. Ratto and Boler provide the example of Occupy Wall Street (2014), where protestors camped in New York's financial district to draw attention to financial inequality and injustice, developing “distinctly DIY organizational processes, 
values, and norms" to run their camp and campaign (p5). Under the DIY Citizenship umbrella, Jenkins describes the work of the Harry Potter Alliance (2014), which inspires and coordinates "real-world" activism based on the values and content of the Harry Potter books and films and the fellowship of their fans (fan activism). Hartley (1999) adopted the term DIY Citizenship from DiY (Do-it-Yourself) culture (McKay, 1998), describing alternatives to both commercial and institutionally-organised arts and politics, from raves to road protests. Thus the concept carries an emphasis on play, as well as creating objects and spaces with political angles. Mann (2015) describes yarnbombing as a type of play which draws renewed attention to public spaces in "micro-political gestures".

\section{Spatial boundaries and audience}

A well-defined sense of place implies certain behaviours (Harrison \& Dourish, 1996; Leszczynski, 2015). Goffman uses the theatre as a metaphor to describe this relationship between context and behaviour (1971/1959), dividing our social experiences into two, non-exclusive, regions: the front region (where performance is the focus) and backstage (where performers prepare and/or relax). The front region is observed: politeness and decorum are generally expected. Cornwall and Hassan's conceptions of invited space and unspace resemble Goffman's front regions. The backstage region is observed only by the team: here, a wider, more casual range of behaviour is expected. Goffman's theory is based on his ethnographic studies of a Shetland community (1949-51). For many of the situations he describes, backstage and front regions have shifted or even swapped. However, his metaphor abstracts what he observed into a powerful way to describe how certain behaviour is expected in certain situations because of the audience. For participation research, it also alerts us to the concept of backstage preparation work, which supports public events. 
Goffman's situations are defined by a sense of place and who is likely to be interacting or observing. Offline, the physical boundaries of a space help to define the social setting: we can generally make a judgement about the extent to which we are observed and moderate our behaviour accordingly. Online settings are more challenging and it can be difficult to know how to act in a vaguely-defined situation (boyd, 2011): "Having to imagine one's audience is a fundamental human problem rather than one distinctive to social media. But social media make it particularly challenging to understand 'who is out there and when' and raises the potential for greater misalignment between imagined and actual audiences" (Baym \& boyd, 2012, p. 323).

\section{The social public sphere}

Habermas conceived of the public sphere as an abstraction of social assemblies: people gathering and discussing matters of interest to them (1974/1964). He provided the example of early coffee houses, where people came together, reading and discussing news journals. While Habermas' prescriptions for deliberation have fallen from favour (e.g., Loader \& Mercea, 2012; Wright, 2012),, the social and spatial image at the heart of the public sphere still influences conceptions of democratic spaces (e.g. Arora, 2014; Kim \& Kim, 2008; Papacharissi, 2009). Kim and Kim (2008) identify the foundations of the public sphere in everyday political talk. Graham (2012) identifies political talk, including rational deliberation, in online forums about money-saving and reality TV. Coming together to discuss mundane topics helps people to develop their identity within society: Shklovski and Valtysson find publics coalescing via informal discussions in popular online forums in Kazakhstan (2012). Publics that form around de-politicised content are particularly important in countries where online speech is heavily monitored. Baym and boyd suggest that "socially-mediated publicness may be a source of support and empowerment" (2012, p. 325). 
Online spaces which bring people together around a shared, but not political, interest gather a more diverse range of people than political spaces; this enables less polarised discussions (Wright, 2012) and a wider range of communication styles (Graham, 2012). Hartley (2010) emphasises the role of play, including music and comedy. While these have a long history of democratic influence, Internet technologies enable wider participation and diffusion, for example through cameras and editing applications on phones. These spaces can bypass established power structures: Cohena and Raymond (2012) studied discussions on Internet forums for pregnant women and concluded that these forums empowered women to exchange information and support, peer-to-peer, rather than relying on partial or hierarchical information distribution from the medical profession.

\section{Sociotechnical assemblages}

A participation space is more than a container or location for activities - it is all the diverse elements that constitute the space. This echoes both Deleuze and Guattari's concept of the assemblage (2004) and Massey's work on physical spaces (2005). Massey, a geographer, describes space as the "product of interrelations" (2005, p. 9). In assemblages, the interactions between elements are the focus, rather than preconceived hierarchical systems (Deleuze \& Guattari, 2004). When applied to the context of technology, this supports an understanding of technology as a composite of diverse elements - rather than an atomistic device, an abstract force, or a neutral online space. Participation spaces include human elements, such as actors, processes and content; they may include digital elements, such as code; and/or material elements, such as windows. Economic and historical aspects also form the space. Massey observes that space is always under construction, "a simultaneity of stories-so-far" (2005, p. 9). Bucher observes that Deleuze and Guattari's assemblages echo the French 
understanding of agencement, which concerns the process of assembling (2013).

Suchman investigates humans and artefacts working together and describes these configurations as sociotechnical assemblages (2007). Observing these assemblages, one element or another seems to have agency at any moment, but this agency is an effect of interaction, rather than a property of any individual element. Orlikowski provides the dynamic example of a Google search, as a sociomaterial assemblage (2007). Each search includes the activities of many devices and connections, plus software (including algorithms), and content, all combined with organisational practices. For example, EU regulation may be visible in a Google search assemblage, as Google responds to the "Right to be Forgotten" (Google Spain v. AEPD, 2014, para. 94; Youm \& Park, 2016). Kitchin proposes considering big data as a data assemblage, including: systems of thought, forms of knowledge, finance, political economy, governmentalities and legalities, materialities and infrastructures, practices, organisations and institutions, subjectivities and communities, places, marketplace (2014, p. 25).

The interactions of an assemblage stretch into the wider context and back in time, as social practices, economic factors, and historical activities influence (and become) the constituent elements of the assemblage. The differences and boundaries between humans and machines are continually shifting: boundaries exist $a$ s they are enacted (Barad, 2003; Suchman, 2005). In this way the boundaries of a participation space may be physical, virtual, social, and/or temporal; they are likely to be mutable, permeable and subjective.

\section{Socio-technical interaction networks}

Kling and colleagues had been working on ways to conceptualise computer systems, holistically. In Kling and Scacchi's web model (1982), each system is an ensemble of 
equipment, applications, and practices. The system requires (and thus includes) people, and their goals and associated skills. Historical elements are also included, because choices in the history of a system affect its characteristics. The nature and configuration of all these elements into a specific computer system is not separable from its context (Kling \& Scacchi, 1979).

The web model evolved into Kling, McKim, and King's Socio-Technical Interaction Network (STIN) (2003), developed within investigations into information infrastructures designed to support collaboration between distributed academics. The STIN approach conceives of the system being studied as a metaphorical network of all the elements involved. These are likely to include people, groups, devices, infrastructures, resources, processes, content, and policies. As in assemblages, the constituent elements are considered as interactors, the networks are dynamic, and the focus is on the relationship between elements. The histories of elements within the STIN influence the present and future systems, and need to be identified and considered within the analysis. STIN is both a metaphor to understand an information system as a network of heterogeneous elements and a framework for analysing the system (Kling, McKim, \& King, 2003; Meyer, 2006). The STIN framework was chosen to capture and model participation spaces due to its holistic approach, which reflects socio-technical concepts of assemblages and the complexities of participation. The over-arching aim is to increase understanding of the role of the Internet within democracy by exploring the day-to-day activities of people working to improve their communities, focusing on the relationship between activities and contexts. It is a sociotechnical study, a contribution to the myriad studies needed to build a composite picture of the evolving relationship between technology and democracy in our societies. Kling promoted tackling questions about social and technical influences through empirical studies of ICTs in the settings in 
which they are used: "credible and compelling narratives about the social roles of technologies" (Kling, 1992, p. 353).

\section{Methodology}

\section{Case studies of community and activist groups}

The research is guided by the following questions:

(1) What spaces are considered, used or created for participation, by people trying to improve their local communities?

(2) What characteristics of these spaces influence their use as participation spaces?

(3) What characteristics of people and groups influence their choices and uses of participation spaces?

The research questions were pursued through three case studies. Each case concerned a group working to influence their local council and environment, in Scotland. Citizen-led initiatives provide good opportunities to explore democratic behaviour, as people have more control over their actions than in initiatives organised by institutions (Cornwall, 2000). Case Study 1 (Anti-Cuts Group ${ }^{1}$ ) concerned an established local group who campaigned against austerity and privatisation. In the casestudy period, this group were campaigning against the implementation of the bedroom $\operatorname{tax}^{2}$ and around changes to the provision of care services. The second case-study group were working to improve Hill Village, with a particular focus on sustainable energy. Projects within the case-study period included building a carbon-neutral resource centre, involvement in a windfarm proposal, and improving paths in local woodland. Case Study 3 (Primary School Parents) centred on a group of parents who were campaigning against the commercial development of an old high school building which adjoined the primary school and its playground. Property developers had bought the building from 
the council, subject to receiving planning permission to convert it from unused offices into studio apartments.

The methodology, influenced by ethnography, aimed to build understandings of both participation and technology according to the activities, values, and motivations of the people involved. To this end, the methods centred on participant observation (on and offline), interviews with people involved in the groups, and reviewing materials created by the groups. The three case studies were mostly conducted, consecutively, through 2013. Case Studies 1 and 2 were the focus for around seven months, each. Data gathering in Case Study 3 focused more on interviews looking back at the campaign; the researcher had also observed the campaign in action during the previous year. Thirty-three semi-structured interviews were conducted across the three cases, with each interview lasting about an hour.

Participation was recognised as the activities people did to further the aims of their group (to improve their local communities and environments), in contrast to studies which identify or evaluate participation according to ideals (e.g. Arnstein, 1969). The participation spaces were the fields for in situ observation, as well as the subjects of interviews, and the unit of analysis. For example, the researcher joined Hill Village Facebook Group and read the daily posts, and interviewees discussed its features and use. Permission to join the group was granted by its administrators and the researcher acted to alert group members to her presence (and to the research project) through posts and by attending the village' summer fair wearing a tabard featuring the logos of Facebook, the Hill Village group, and the authors' university.

Textual data, such as observations, interview transcripts, and public social media posts, was collated; then iteratively analysed and themed. In this way, participation spaces were identified, along with activities which took place within and around them. 
Following Cornwall's suggestion to treat participation as situated practice (2002), participation spaces were determined according to what the groups did and aimed to do. The functions of the activities, as observed, could be summarised as: organising and solidarity, sharing information, encouraging involvement, and trying to influence events. The concept of space was interpreted broadly, to include websites; blogs; social media accounts, groups and spaces; email lists; and offline locations, such as rooms. The resulting longlist of participation spaces answered the first research question (though not exhaustively). In order to scope the research, nineteen spaces from the longlist were chosen for analysis, through an iterative process of modelling pilot spaces. Spaces which were sparsely used were not modelled beyond the pilot phase. Spaces which captured the groups' activities were prioritised. These were:

(1) Anti-Cuts Group: the group's Facebook Page; their Twitter account; email list; the Alliance Blog; paper flyers; meeting room in local Community Centre.

(2) Hill Village Trust: Hill Facebook Group; Hill Facebook Page; Hill Twitter; WordPress Blog; Hill.org website; Directory Magazine; Hill Village Trust Office.

(3) Primary Parents' Group: Parent Council Facebook Group; Reply-All email list; the city's online planning portal; Hyperlocal Paper; the school playground; the City Chambers.

The Facebook Groups were closed — only available to Facebook members who had been approved as group members; the Facebook Pages were public, though not particularly accessible to people who did not use Facebook. The researcher joined Hill Village Facebook Group in Case Study 2 (see above). Data about the Facebook Group in Case Study 3 was gathered in interviews and workshops (see below). 


\section{Modelling participation spaces as STINs}

The participation spaces were understood as socio-technical interaction networks (STIN). The STIN framework provides eight steps (heuristics) to identify the elements that constitute the system (in this case, the participation space) and to explore the relationships between these elements (Kling, McKim, \& King, 2003). These are designed to surface the characteristics that are influential to the sustainable use of ICTs (Information Communication Technologies). The following list of heuristics is annotated in parentheses to provide clarifications for the context of participation. Interactors include non-human actors such as devices or regulations.

(H1) Identify interactors (actors and roles).

(H2) Identify core interactor groups.

(H3) Identify incentive structures (motivations).

(H4) Identify excluded actors and undesired interactions.

(H5) Identify existing communications systems and their relationships to this STIN (groups and networks, media, other participation spaces).

(H6) Identify resource flows (who pays, who is paid, fundraising).

(H7) Map architectural choice points (technological features or social arrangements chosen in the past, leading to the current arrangements).

(H8) Describe viable configurations and trade-offs.

Each participation space was modelled by responding to these heuristics in text and then further exploring certain elements in diagrams. For example, the interactors for a space were listed in text and then the space was drawn as a map of these interactors. This was an iterative process, helping to identify the interactors and understand their relationships. These diagrams encapsulate the network metaphor at the centre of the STIN; they are not process diagrams or directed graphs (Kling, McKim, \& King, 2003). 
There is a strong parallel between the use of diagrams in this study and Clarke's use of situational maps with grounded theory: Clarke's maps work as discursive devices, for understanding assemblages and making connections (2005, p. 30). The STIN diagrams also provided ways to share the models with colleagues and with people in the casestudy groups. Figure 1 shows the interactors' diagram for the Anti-Cuts group's email list. This was not a hosted discussion or distribution list; rather, the group's chair, Jean, kept a text file of email addresses, sending emails to the addresses on this list, using Bcc.

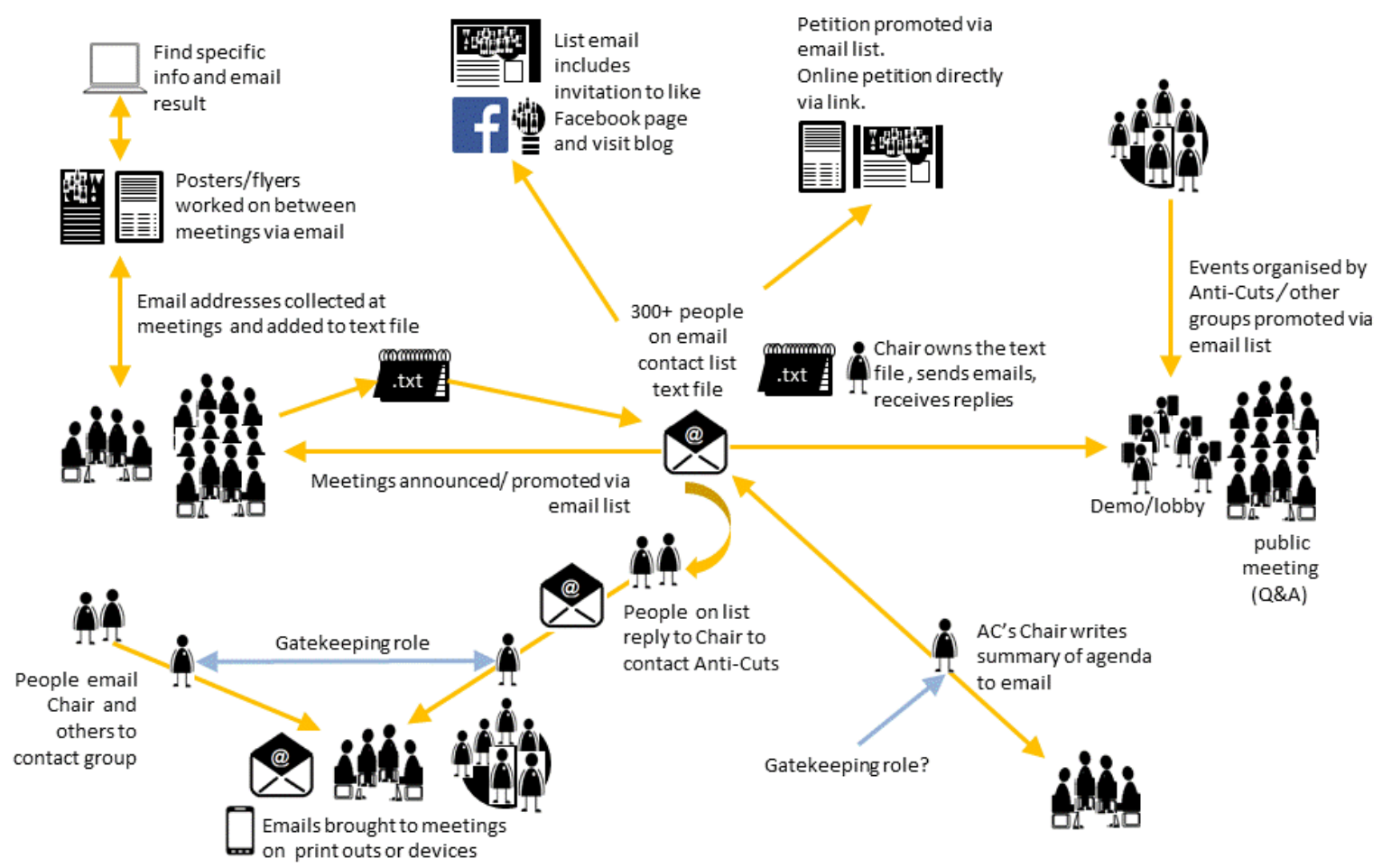

Figure 1: Anti-Cuts group's Bcc email list

Timelines were created for some spaces. These illustrated responses to H7 (map architectural choice points), but also described activities in the case-study time period, illustrating the relationship between each group's participation spaces, and between spaces and events.

The people involved in each case-study group are considered to be experts in participation in the contexts of their lives and their group, and presumed to have 
knowledgeable and valuable opinions about the outputs of the research. So, workshops were organised in which STIN diagrams were used, innovatively, to collaborate with participants around initial results: to share insights with the case-study groups and get feedback about the information presented. Two participation spaces were represented by their interactors' diagrams (printed at A1 size) at each workshop. Participants discussed this presentation of their work and annotated the diagrams. Participants accepted the pictures and also provided additional information, including clarification, trajectories, and some omissions. There is a parallel here with the rich pictures created within Soft Systems Methodology (Checkland, 2000) as aids to understanding situations, and tools to share and check this understanding with participants. Checkland describes this style of validation: "This is how we see this situation at present, its main stakeholders and issues. Have we got it right from your perspective?" (2000, p. 22). Understanding the participation spaces through maps also reflects this study's spatial theme.

\section{Findings}

\section{The spatial characteristics which influence participation}

The STIN models provide a structured picture of how the participation spaces supported democracy and why participants chose to use each different space. Each model collated data in response to the eight STIN heuristics, even if the data was rather prosaic. Star advocates this approach: "let us also attend ethnographically to the plugs, settings, sizes, and other profoundly mundane aspects of cyberspace, in some of the same ways we might parse a telephone book" (1999, p. 379).

The first research question was answered in the identification of participation spaces used by the groups (above). The findings from the STIN models address the second and third research questions: What characteristics of these spaces influence their 
use as participation spaces? What characteristics of people and groups influence their choices and uses of participation spaces? The findings reflect the use of a spatial metaphor (the participation space) and sociotechnical analysis framework (STIN). The characteristics of online and offline spaces that influence people's participation are the spaces' apparent boundaries and potential inhabitants, combined with the ownership and resulting identity of each space, including who pays for what.

\section{Defined boundaries and visible inhabitants}

The participation spaces which were used most were those with defined boundaries and visible inhabitants, such as offline spaces and closed Facebook Groups. These boundaries meant that participants knew who was potentially in the space- the potential audience for posts. Offline participation spaces, such as meeting rooms, had physical boundaries and the inhabitants could generally see each other's reactions, as well as identifying their audience. Where possible, offline spaces were preferred for all tasks: organising (especially making important decisions), involving people, and influencing events. However, the overhead of needing to be in the same place at the same time limited their use. Castells describes how structure and organisation in the Network Society still respond to space and time, but are transformed by ICT networks' support for distributed interaction (1997).

The two closed Facebook Groups had visible boundaries because group members could see a list of members, each linked to the public elements of that person's profile. These non-public ${ }^{3}$ groups were used extensively, supporting discussion and information-sharing. Participants who disliked Facebook doubted the Facebook's Group's boundaries and used the groups reluctantly, if at all. Some felt the boundaries might be porous; others worried about potential boundary-breaches across areas of their lives. This scepticism towards the boundaries of online spaces casts doubt on our ability 
to identify these spaces as a binary public or private (Nonnecke, Andrews, \& Preece, 2006).

Within the models of participation spaces, the boundaries of the email lists were understood in terms of the recipients' email addresses in the To, $\mathrm{Cc}$ and Bcc fields. Each group's email list worked in a different way. The Anti-Cuts group's email list (CS1) was a text file of email addresses, while the Trust's list (CS2) ran on an email distribution platform. Only the owners of these two lists could see the recipients' email addresses and post to the list. The school parents' used "Reply-All" to create their "list" (CS3), so the recipients' email addresses were visible to everyone and everyone could post to the list. These visible email addresses — the list's visible boundary_influenced people's use. People liked the transparency, but were reluctant to send unnecessary emails to so many people, or to specific people (e.g. people whose professional roles were highlighted within their email addresses). The lists' boundaries are dynamic, enacted each time an email is sent (cf. Barad, 2003; Suchman, 2005).

Websites, blogs, and public social media, like Twitter and Facebook Pages, provide few boundaries between content and potential audience. Content-creators do not know who will see their posts and comments. Most people were reluctant to post in this context. Thus, while many people posted in non-public online spaces, public online spaces, such as blogs and Facebook pages, were maintained by individuals and garnered very few comments. If this study only used public online participation spaces as data sources, most of the groups' online communications would be missed, resulting in a distorted picture of their work.

The bounded spaces supported groups to collaborate on developing their understanding of issues and processes. Cycles of individual learning from external sources, combined with group discussion (offline or in non-public online spaces), and 
enabled the groups to develop deep understandings of their issues and to formulate potential solutions and related actions. Deliberation within the group was an organisational activity, whether in terms of discussing issues or campaign strategies. It was not a performance, nor an ideal of Habermasian argumentation. Non-public participation spaces, on and offline, were equivalent to Goffman's backstage regions, where performers prepare. The groups' preparation consisted of organising and learning.

Public participation spaces (such as public meetings and demonstrations, websites, blogs, and public social media) resembled front regions. Here the participants presented the results of their preparations - presentations, petitions, flyers, posters, events - to the public and people in power. Public campaigning contexts, such as events, meetings, and distributing flyers, were less firmly bounded than non-public situations. However, as initiators of the situation, participants could, to some extent, define the contexts. The groups established the location, themes, and format of public meetings; they controlled the content of flyers and information stalls. This was echoed in public online contexts: group leaders provided content, which others could respond to.

As well as preparing for performances, Goffman describes people relaxing in backstage regions. In parallel, non-public participation spaces supported vital social interactions, which may have contained useful information and/or contributed to group solidarity. Social communications were important in encouraging people to visit certain participation spaces, whether turning up to a friendly group meeting, logging into Facebook, or even checking email. 


\section{Ownership, identity, and cost}

The groups favoured free participation spaces; of the three groups, only the Hill Village group (CS2) was financed. The Anti-Cuts group and school campaigners met offline in spaces they did not need to pay for, such as the Community Centre and the pub opposite the school. Online, all three groups favoured email and free social media. There are costs associated with these spaces, but these are diversified to individuals, and payments are subsumed into infrastructural costs, such as taxes and Internet access, rather than for each communicative act: the "parameters of cost move from the foreground to the background" (Madianou \& Miller, 2012, p. 126). This means potential exclusion for those who cannot afford costs like Internet access. In the long term, it is not clear how viable or ethical it is to rely on free social media, supported by advertising. Thus (answering RQ3) the economic characteristics of the groups and their members influenced their choice of participation spaces.

The characteristics of ownership, identity, power, and cost are entwined. City Council's online Planning Portal (in CS3) aims to support citizen involvement in the planning process, as well as supporting professionals, such as property developers and council staff. However, the portal reflects the imbalance of power in the planning process: developers and council staff are trained professionals, navigating the process in paid time, whereas objectors are volunteers, learning and participating in their own time. Further, City Council defines the criteria for admissible objections, which may not reflect the concerns of local residents. These may be considered a kind of dispositif: Foucault's concept of the material and social (institutional and organisational) structures and processes which maintain the exercise of power (Foucault 1991, cited by Bowker \& Star, 1999, p. 38; Pløger, 2008).

For Facebook members, ownership and identity are complex. Facebook group posts appear in members' newsfeeds next to posts from friends; emotions and customs 
are likely to overlap, including liking, using emoticons, and posting supportive comments or "pithy one-liners" (CS3 interview). Facebook spaces are continually recreated by software (Kitchin \& Dodge, 2011), responding to the activities of members. Where people feel ownership of a space, they bring their own customs and processes; whereas, in invited spaces, people need to adopt the customs and processes of the space's owners; they may be less confident using these and their range of communication is reduced (Cornwall, 2000). This parallels Goffman's regions. Notably, the Hill Facebook Group is not owned by the improvement group; in interviews its members called it "the Community Facebook Group".

\section{Social elements encourage visits and posts}

Social interactions are expected in offline spaces, as people greet each other at the beginning of meetings or chat at the end. A social occasion, like Hill Summer Fair, provides a good opportunity for the improvement group (CS2) to share their plans. Online interactions can easily lose social elements, as content-creators focus on their information-sharing goal. One advantage of Facebook may be that sociality is designed in, as associates are designated friends and the easiest interaction is to like a post. On the Hill Facebook Group, social interactions were interspersed with queries and information sharing, in a similar way to a friendly offline situation. People visited regularly, informally, voluntarily, newcomers were welcomed, and regulars used humour to manage conflict. Case study 3 interviewees valued supportive comments and emoticons in the Parent Council Facebook Group, especially compared to their email list. The few comments on the Facebook Pages of the Anti-Cuts group and Hill Village tended to be short and social, supportive or humorous. 
Less social online participation spaces were used in a more goal-oriented way. Jean (CS1) sent out the Anti-Cuts' list email, specifically to remind people about their regular meeting. Parent campaigners (CS3) visited City Planning Portal to find information or to object to the planning application.

\section{Integrated use of participation spaces}

The participation spaces designation is useful for encapsulating the sociotechnical assemblages which are used by the groups for participation. It supports comparisons between online and offline spaces and helps to identify bounded phenomena that can be described as STINs. However email and email lists are experienced differently in spatial terms than an offline room or website. Flyvbjerg suggests that atypical cases, like these, are likely to reveal more processes than typical cases (2006).

The metaphors which govern email do not pertain to shared space, but to messages, which are sent from one person's inbox to another's. In this way, email is bounded by its sender and recipients. In the case studies, only those with access to the list of email recipients could email the group. In the Primary Parents' Reply-All list, the recipients' visible email addresses, individual and as a quantity, influenced people's willingness to post to the list. By being at the edge of the participation spaces conception, email sheds additional light on how the boundaries of participation spaces are perceived and the influence of these boundaries on that space's use.

Email was essential to all the groups, because it linked participation spaces and linked people who were not co-located. It helped to bring people into participation spaces, especially from offline spaces where email addresses were collected. Given this linking role, perhaps email should be regarded as an infrastructure of participation. The STIN studies reveal that email underpinned most of each groups' activities. Email was 
used for organising and involving people. It was crucial for influencing people in power, whether by inviting them to take part in a public question and answer session or asking them to act on an issue.

All the participation spaces could be considered as infrastructural elements: none were atomistic, and a primary use of many of the spaces was to link to content in another space. The interactors' diagram for each space includes the other participation spaces for that case study. This pattern of integrated media use resembles Madianou and Miller's polymedia model (2012). Each case-study group existed in an ecology of media, including participation spaces, and these media came to be constituent parts of the group. Participants continually made choices about which media to use for each task. Once costs moved into the background (e.g., in social media, email, and blogs), this choice was based on the affordances of the media, combined with emotional or moral considerations about appropriate use. This article describes these affordances and considerations in terms of spatial characteristics.

\section{Conclusions}

The participation space concept supports the reification of the online and offline contexts of grassroots democracy. The case studies provided detailed examples of participation spaces and the STIN approach enabled the systematic modelling of these spaces, including all the diverse elements that constitute each space. The ethnographic approach to data collection prioritised understanding the participation spaces within the contexts of the case-study groups - their aims and activities, histories, locations and communities. In this way, online spaces, including email and social media, could be investigated, empirically, with offline spaces that were used for similar purposes, revealing that the same factors influence the spaces' use. Although this article describes grassroots participation in mostly informal locations, the study is not divorced from 
representative democracy. The three case-study groups interacted with their representatives, in participation spaces, and each group had some formal success in reaching its goals.

The relationship between Internet spaces and democracy is often described in utopian or dystopian scenarios (Papacharissi, 2011). Online democracy becomes unattainably idealised in the online public sphere (Loader \& Mercea, 2012); contemporary social media become threats to democracy (e.g. Marichal, 2012; Marwick \& Lewis, 2017). However, the participation spaces in this study are real (albeit abstracted) places and not intrinsically bad places. The challenges of democratic participation in online spaces such as social media are not insurmountable, but they need to be understood and then addressed (Tufekci, 2016). This article contributes to that understanding.

In this study, Facebook groups supported people from different social worlds to come together based on a shared interest, such as their village or their children's school. As these interests are not essentially political, the groups included people with a wide range of views, potentially enabling non-polarised discussions. Rather than being filter bubbles (Parisier, 2012), the Facebook Groups could be seen as boundary objectsinformation objects which support collaboration of people from different social worlds (Bowker \& Star, 1999; Star \& Griesemer, 1989). Because none of the group members paid for the space directly, the Facebook Groups could be experienced as community groups with shared ownership.

The participation space models also provide insights into the day-to-day activities of participation. Most of the groups' activities took place in non-public contexts, such as closed Facebook Groups, email, and face-to-face meetings. Like an iceberg, with publicly visible events and campaigns above the waterline, the majority of 
participants' work was out of public view, on and offline (Taylor-Smith \& Smith, 2016). This non-public participation included extensive learning and preparation, supporting a smaller amount of visible public action. This provides quite a different view of democracy to studies based on public Internet posts (e.g. Quinlan, Shephard, \& Paterson, 2015), especially big data studies.

Finally, the participation space concept provides an accessible way to talk about online and offline contexts with research participants and the general public. Models of participation spaces were shared with people from the case-study groups in workshops, presented as diagrams; whereas, in this article, the spaces are presented as STINs, sociotechnical assemblages, regions for preparation or performance, participation infrastructures, and potentially boundary objects.

\section{References}

Arnstein, S. (1969). A ladder of citizen participation. Journal of the American Institute of Planners, 35(4), 216-24.

Arora, P. (2014). The Leisure Commons: A spatial History of Web 2.0. London: Routledge.

Barad, K. (2003). Posthumanist Performativity: Toward and understanding of how matter comes to matter. Signs: Journal of Women in Culture and Society, 28, 801-831.

Baym, N.K., \& boyd, d. (2012). Socially Mediated Publicness: An Introduction. Journal of Broadcasting \& Electronic Media, 56(3), 320-329. DOI: $10.1080 / 08838151.2012 .705200$

Bennett, W.L. \& Segerberg, A. (2012). The logic of connective action. Digital media and the personalization of contentious politics. Information, Communication \& Society, 15(5), 739-768.

Bowker, G. \& Star, S.L. (1999). Sorting Things Out: Classification and Its Consequences. California: MIT Press.

boyd, d. (2011). Dear voyeur, meet flâneur...Sincerely, social media. Surveillance and Society, 8(4), 505-507. 
Bucher, T. (2013). The Friendship Assemblage: Investigating Programmed Sociality on Facebook. Television \& New Media, 14(6). 479-493. DOI:

$10.1177 / 1527476412452800$

Castells, M. (1997). An introduction to the information age. City, 2 (7). Pp.6-16.

Reprinted in F. Webster (ed.) (2004), The Information Society Reader (pp.138149). London: Routledge.

Checkland, P. (2000). Soft Systems Methodology: A Thirty Year Retrospective. Systems Research and Behavioral Science, 17 (S1), 11-58.

Clarke, A. (2005). Situational Analysis: Grounded Theory After the Postmodern Turn. Thousand Oaks, California: SAGE.

Cohena, J.H., \& Raymond, J.M. (2012). How the Internet is Giving Birth (to) a New Social Order. In B. Loader \& D. Mercea (eds.), Social Media and Democracy. Innovations in participatory politics (pp.224-240). London: Routledge.

Cornwall, A. (2000). Beneficiary, Consumer, Citizen: Perspectives on Participation for Poverty Reduction. Stockholm: Sida Studies 2.

Cornwall, A. (2002). Locating Citizen Participation. IDS Bulletin, 33(2), 49-58.

Cornwall, A. \& Coelho, V.S.P. (2007). Spaces for change? The politics of citizen participation in new democratic arenas. London: Zed.

Dahlberg, L. (2001). Extending the Public Sphere through Cyberspace: The Case of Minnesota E-Democracy. First Monday, 6(3). Retrieved from: http://firstmonday.org/ojs/index.php/fm/article/view/838/747

Deleuze, G. \& Guattari, F. (2004). A Thousand Plateaus: Capitalism and Schizophrenia (B. Massumi, Trans. New ed.). London: Continuum.

Dodge, M. \& Kitchin, R. (2001). Mapping cyberspace. London and New York: Routledge.

Flyvbjerg, B. (2006). Five Misunderstandings About Case-Study Research. Qualitative Inquiry, 12(2), 219-245.

Goffman, E. (1971). The presentation of self in everyday life. Harmondsworth: Penguin. (Original work published 1959).

Google Spain SL, Google Inc. v. Agencia Española de Protección de Datos (AEPD), Mario Costeja González. Case C-131/12, Court of Justice of the European Union (Grand Chamber). (2014, May 13). 
Graham, T. (2012). Beyond "Political" Communicative Spaces: Talking Politics on the Wife Swap Discussion Forum. Journal of Information Technology and Politics, $9(1), 31-45$.

Habermas, J. (1974). The Public Sphere: An Encyclopaedia Article (1964). New German Critique, 3, 49-55.

Harrison, S. \& Dourish, P. (1996). Re-Place-ing Space: The Roles of Place and Space in Collaborative Systems. In G. Olson, J. Olson \& M. Ackerman (Eds.), CSCW '96 Proceedings of the 1996 ACM conference on Computer supported cooperative work, (pp. 67-71). New York: ACM.

Hartley, J. (2010). Silly Citizenship. Critical Discourse Studies, 7(4), 233-248.

Hassan, G. (2014). Independence of the Scottish mind elite narratives, public spaces and the making of a modern nation. Basingstoke: Palgrave Macmillan.

Jenkins, H. (2014). Fan Activism as Participatory Politics: The Case of the Harry Potter Alliance. In M. Ratto, \& M. Boler (Eds.), DIY Citizenship: Critical Making and Social Media. (pp.65-74). Cambridge, MA: MIT Press.

Kim, J. \& Kim, E.J. (2008). Theorizing Dialogic Deliberation: Everyday Political Talk as Communicative Action and Dialogue. Communication Theory, 18, 51-70.

Kitchin, R. \& Dodge, M. (2011). Code/Space. Software and Everyday Life. Cambridge, MS and London: MIT Press.

Kitchin, R. (2014). The Data Revolution: Big Data, Open Data, Data Infrastructures and Their Consequences. London: Sage.

Kling, R. (1992). Audiences, Narratives, and Human. Values in Social Studies of Technology. Science, Technology, \& Human Values, 17(3), 349-365.

Kling, R., McKim, G., \& King, A. (2003). A Bit More to IT: Scholarly Communication Forums as Socio-Technical Interaction Networks. Journal of the American Society for Information Science and Technology, 54(1), 46-67.

Kling, R. \& Scacchi, W. (1979). Recurrent dilemmas of computer use in complex organisations. In R. Merwin and J. Zanca (eds.), Proceedings of the National Computer Conference, New York, June 4-7, 1979. Montvale, NJ: AFIPS Press, 107-116.

Leszczynski, A. (2015). Spatial media/tion. Progress in Human Geography, 39(6), 729751. 
Loader, B. \& Mercea, D. (2012). Networking Democracy? Social media innovations in participatory politics. In B. Loader, \& D. Mercea (Eds.), Social Media and Democracy. Innovations in participatory politics (pp. 1-10). London: Routledge.

McKay, G. (1998). DiY culture: Notes towards an intro. In G. McKay (Ed.), DiY culture. (pp.1-53). London: Verso.

Madianou, M. \& Miller, D. (2012). Migration and New Media: Transnational Families and Polymedia. New York: Routledge.

Mann, J. (2014). Towards a politics of whimsy: yarn bombing the city. Area, 47(1), 6572.

Marichal, J. (2012). Facebook Democracy. The Architecture of Disclosure and the Threat to Public Life. Surrey: Ashgate.

Marwick, A. \& Lewis, R. (2017). Media Manipulation and Disinformation Online. Data \& Society. Retrieved from: https://datasociety.net/output/media-manipulationand-disinfo-online/

Massey, D. (2005). For Space. London: Sage.

Meyer, E. T. (2006). Socio-technical Interaction Networks: A discussion of the strengths, weaknesses and future of Kling's STIN model. In J. Berleur, M.I. Numinen, and J. Impagliazzo, (Eds.), IFIP International Federation for Information Processing, Volume 223, Social Informatics: An Information Society for All? In Remembrance of Rob Kling (pp.37-48). Boston: Springer.

Nonnecke, B., Andrews, D., \& Preece, J. (2006). Non-public and public online community participation: Needs, attitudes and behaviour. Electronic Commerce Research-ECR, 6(1). 7-20.

Orlikowski, W.J. (2007). Sociomaterial Practices: Exploring Technology at Work. Organisation Studies, 28(9). 1435-1448.

Pariser, E. (2012). The filter bubble: What the Internet is hiding from you. London: Penguin.

Papacharissi, Z. (2009). The Virtual Sphere 2.0: The Internet, the Public Sphere and beyond. In A. Chadwick, \& P. Howard (Eds.), Handbook of Internet Politics. London: Routledge.

Papacharissi, Z. (2011). On convergent supersurfaces and public spheres online. International Journal of Electronic Governance, 4(1/2), 9-17. 
Pløger, J. (2008). Foucault's dispositfis and the city. Planning Theory, 7(1). 51-70. DOI: $10.1177 / 1473095207085665$

Quinlan, S., Shephard, M., \& Paterson, L. (2015). Online discussion and the 2014 Scottish Independence Referendum: Flaming Keyboards or Forums of Deliberation? Electoral Studies, 38(June 2015), 192-205.

Ratto, M. \& Boler, M. (2014). Introduction. In M. Ratto, \& M. Boler (Eds.), DIY Citizenship: Critical Making and Social Media. (pp.1-22). Cambridge, MA: MIT Press.

Shklovski, I. \& Valtysson, B. (2012). Secretly Political: Civic Engagement in Online Publics in Kazakhstan. Journal of Broadcasting \& Electronic Media, 56(3), 417-433.

Star, S.L. (1999). The Ethnography of Infrastructure. American Behavioral Scientist. 43(3), 377-391.

Star, S.L. \& Griesemer, J. (1989). Institutional ecology, "translations" and boundary objects: amateurs and professionals in Berkeley's Museum of Vertebrate Zoology. Studies of Social Science. 19(3), 387-420.

Suchman, L. (2005). Agencies in technology design: Feminist reconfigurations. Article presented at the workshop on gendered innovations in science and engineering, Stanford University, $15^{\text {th }}$ April, 2005.

Suchman, L. (2007). Human-machine reconfigurations: Plans and situated actions, (2nd ed.). Cambridge, MA: Cambridge University Press.

Taylor-Smith, E. \& Smith, C. F. (2016). Non-public eParticipation in Social Media Spaces. In A. Gruzd, J. Jacobson, P. Mai, E. Ruppert \& D. Murthy (Eds.). Proceedings of Social Media and Society (SMSociety '16). ACM.

Tufekci, Z. (2016, November 12). Mark Zuckerberg is in Denial. The New York Times. Retrieved July 10, 2017, from http://www.nytimes.com/2016/11/15/opinion/mark-zuckerberg-is-in-denial.html

Williamson, A. (2011). Disruption and Empowerment: Embedding citizens at the Heart of Democracy. JeDEM, 3 (1), 22-32.

Wright, S. (2012). From 'third place' to 'Third Space': everyday political talk in nonpolitical online spaces. Javnost, 19(3), 5-20. 
Youm, K.H. \& Park, A. (2016). The "Right to Be Forgotten" in European Union Law. Journalism \& Mass Communication Quarterly, 93(2), 273-295.

\section{Notes}

1. This research followed Edinburgh Napier University's ethics procedures. All participants (people, groups, and places) have been anonymised.

2. The bedroom tax is a popular name for a UK policy to reduce housing benefit according to the number of bedrooms in the property: it is not an actual tax. The policy took effect in April 2013.

3. The term non-public is adopted from Nonnecke, Andrews and Preece, who use the term to describe lurkers in discussion forums (2006). It is used here to reflect the uncertain privacy levels of online communications. 